\title{
O FEMINISMO NO ÂMBITO DAS RELAÇÕES INTERNACIONAIS: OCIDENTE X ORIENTE E 0 PROTAGONISMO DA MULHER MUÇULMANA
}

\author{
FEMINISM WITHIN INTERNATIONAL RELATIONS: \\ WEST X EAST AND MUSLIM WOMAN PROTAGONISM
}

\author{
Nielle Figueiredo ${ }^{1}$ \\ Neylane Naually Souza Ferreira ${ }^{2}$ \\ Brenda Thainá Cardoso de Castro ${ }^{3}$
}

\begin{abstract}
RESUMO: O protagonismo da mulher muçulmana no contexto da relação entre Ocidente x Oriente baseia-se na difusão do relativismo da Declaração dos Direitos Humanos, no entanto, aqui será levantada a discussão de que os direitos das mulheres devem ser vistos sob a ótica do universalismo e o debate da nova consciência de gênero emergente no feminismo islâmico. É reconhecido, neste ensaio, o pluralismo cultural do Islã e as divergências na visão dos estudiosos que tomam o seu referencial cultural e, por vezes, julgam erroneamente uma cultura rica em significados simbólicos.
\end{abstract}

Palavras-Chave: Feminismo Islâmico. Pluralismo Cultural. Mulher. Ocidente. Oriente.

\begin{abstract}
The role of Muslim women in the context of the relationship between West and East is based on the diffusion of relativism of the Declaration of Human Rights, however, here will be raised the discussion that women's rights should be seen from the perspective of universalism and the debate the new consciousness of emerging gender in Islamic Feminism. In this essay, the cultural pluralism of Islam and the divergences in the view of scholars, who take their cultural reference and sometimes misjudge a culture rich in symbolic meanings, is recognized.
\end{abstract}

Keywords: Islamic Feminism. Cultural pluralism. Woman. West. East

\section{INTRODUÇ̃̃O}

Apesar de o feminismo islâmico não ser um termo amplamente difundido por fatores como, por exemplo, a visão homogeneizadora do Ocidente acerca do Islamismo - que

\footnotetext{
${ }^{1}$ Nielle Figueiredo é Bacharel em Relações Internacionais pela Universidade da Amazônia - UNAMA e acadêmica do programa MBA International Business na Universidade do Alto Vale do Itajaí - UNIVALI. Link para o Currículo Lattes: http://lattes.cnpq.br/8528072057628893. ORCID ID: https://orcid.org/0000-00018790-1909. Email: nielle.figueiredo@terra.com.br.

2 Neylane Naually Souza Ferreira é Bacharel em Relações Internacionais pela Universidade Católica de Brasília - UCB e acadêmica do programa de MBA International Business na Universidade do Alto Vale do Itajaí - UNIVALI. ORCID ID: https://orcid.org/0000-0002-5822-4491. Plataforma Lattes: http://lattes.cnpq. br/6913599374421612. Email: neylaane@gmail.com.

${ }^{3}$ Brenda Thainá Cardoso de Castro é Doutoranda no Programa de Pós-Graduação em Sociologia e Antropologia (PPGSA/UFPA). Mestre em Ciência Política (PPGCP/UFPA) e Bacharel em Relações Internacionais (UNAMA). Professora Adjunta do Bacharelado em Relações Internacionais da Universidade da Amazônia (UNAMA) e Coordenadora do Grupo de Estudos de Gênero e Relações Internacionais (GENERI). Link para o Currículo Lattes: http://lattes.cnpq.br/2908080678075385. ORCID ID: https://orcid.org/0000-00018081-0406. Email: brenda.tcc@gmail.com.
} 
assume este como um todo coeso de pessoas que vivem rigorosamente valores muçulmanos - o feminismo nessas sociedades clama por transformações dentro da leitura secular e patriarcal do Alcorão no que tange às mulheres e o seu papel na sociedade.

Cila Lima (2014: 676-677) explica que feminismo secular, as feministas e mulheres islamistas possuem uma relação conturbada, ora de tolerância, ora de rivalidade. Nos anos 1920 a 1940, as duas vertentes se mostravam mais alinhadas, pois partilhavam de lutas e metas similares, como o anticolonialismo.

Nos anos 1970 a 1980, porém, as feministas seculares viam as islamistas como reacionárias e conservadoras, apoiadoras das concepções fundamentalistas de subordinação da mulher, e as islamitas acusavam o feminismo secular de estar associado ao colonialismo e à religião judaico-cristã e de ser imoral.

Apesar das diversas distinções feitas dentro da própria leitura do feminismo, o que temos no momento - ao se tratar do Oriente - são reivindicações feministas de mulheres islamistas de várias nacionalidades que clamam por transformações nas interpretações do Alcorão no que se referem ao papel das mulheres nas sociedades, assumindo uma separação entre religião e cultura. Assim, é possível ver que o feminismo islâmico se trata, sobretudo, de uma interseção entre modernidade e a busca por transformação e ressignificação da perspectiva cultural islamista em relação ao posicionamento das mulheres.

O autor Eduardo Szklarz (2010), em seu artigo Sob o véu: o Alcorão é muito mais tolerante com as muçulmanas do que as culturas e os governos de onde vivem, mostra como mudou, ao longo da história, a condição da mulher e afirma que o Islã incorporou e foi influenciado por costumes e crenças das tribos que habitavam o Oriente Médio antes do nascimento do Profeta Maomé. Deste modo, a divisão do trabalho entre os gêneros, por exemplo, esteve presente desde a invenção da agricultura, de forma que, geralmente, as mulheres cuidavam das tarefas domésticas enquanto os homens monopolizavam as esferas políticas, econômicas e a religião.

Com o advento do Islã e, consequentemente, do Alcorão, a condição dessas mulheres melhorou. Entretanto, o grau dessa melhora gera debate, uma vez que a religião deu a elas o direito de ter propriedade, herança e educação e escolher com quem se casar, mas o Alcorão, contudo, santificou direitos superiores aos homens, como punir uma mulher por desobediência, o direito de ter até quatro esposas e a ideia de que a herança da filha é a metade da do filho (Szklarz, 2010).

0 presente trabalho tem por objetivo compreender como a disseminação da "emancipação e liberdade podem ser convertidas em ferramentas de dominação e, principalmente, como o poder da representação é de fato uma ferramenta ideológica e, por isso, sempre disputado no contexto internacional" (Laura Nóra, 2018: 93). Portanto, será analisado dessa forma que, assim como a civilização Oriental — com ênfase na sociedade Muçulmana — não é um grupo homogêneo, o feminismo também não o é. 
Assumir-se-á, aqui, como pressuposto que o Oriente, em especial a sociedade islâmica, é vista pelas sociedades de maneira estereotipada, com uma mistura de elementos que passam pela representação do Islã como ameaçador para um mundo e, que causa estranhamento e indignação. Para isso será utilizada a obra de Edward Said (2007), intitulada Orientalismo: O Oriente como invenção do Ocidente, em que se trabalha o Oriente como sendo uma invenção do Ocidente, que coloca o "outro" em um lugar diferenciado para fins de submissão e dominação imperialista. Este outro, "o bárbaro", é visto de maneira estereotipada e genérica. (Clarissa Franco, 2016:85)

Sendo assim, se tem a interpretação do Oriente como sendo uma definição fruto das relações de dominação através do saber-poder que sempre estiveram presentes nas relações entre o Ocidente e o Oriente. Como coloca Said (2007:31), "tanto quanto o Ocidente, o Oriente é uma ideia que tem uma história e uma tradição de pensamento, um imaginário e um vocabulário que Ihe deram realidade e presença no e para o Ocidente". Por isso, em certa medida, o imaginário oriental reflete o ocidental.

Essa obra é fundamental na análise pós-colonialista, uma vez que existem críticas a respeito de sua demarcação histórica e conceitual com caráter de resistência política, ideológica, cultural, econômica e social face às dominações colonialistas e suas estruturas residuais.

Por fim, é certo que, como consequência da modernidade e o ímpeto em que os postulados ocidentais atravessam as fronteiras, os seus feitos não impactam apenas o lado ocidental do globo, mas também o lado oriental quando a tradição e a modernidade se chocam e a luta pelo reconhecimento do direito da mulher fica cada vez mais intenso.

\section{O FEMINISMO ISLÂMICO E O ANTIORIENTALISMO}

As contribuições feministas tiveram um impacto bastante tardio no âmbito das Relações Internacionais, apesar de apresentarem um estudo epistemológico capaz de fornecer um modo particular de enxergar os eventos internacionais. 0 principal elemento de discussão das feministas está no reconhecimento das desigualdades entre homens e mulheres associadas às diferenças de gênero, ou seja, as autoras dessa vertente preocupam-se em avaliar como os modos predominantes de pensamento tendem a encobrir essas diferenças.

Sandra Harding (1986) traz o fato de que as mulheres se encontram "às margens", observando aqui a sua similaridade com as vertentes pós-coloniais, das relações globais de poder e que isso lhes fornece uma base apropriada para uma "forte objetividade", pois elas não compartilham da cegueira institucionalizada. Ou seja, para a autora, não há um gênero, apenas indivíduos construídos por lutas históricas particulares sobre as quais raça, classe, sexualidade, culturas e grupos religiosos vão incidir no acesso aos recursos e poder.

As dificuldades enfrentadas, porém, pelo feminismo islâmico são ainda maiores. Clarissa de Franco (2016) afirma que tal corrente feminista não é difundida de maneira 
profunda na cultura popular e nem mesmo nas esferas acadêmicas por diversos fatores, mas principalmente pela visão homogeneizadora do Ocidente acerca do Islamismo.

Entretanto, ao se pensar no protagonismo feminino nas civilizações islâmicas, é imprescindível ressaltar que a mensagem do Alcorão tem um princípio mais radical de igualdade de gênero do que outros livros sagrados, mesmo que isso soe contraditório, principalmente ao se comparar com a Bíblia, que é a base da religião mais praticada no Ocidente.

Enquanto o Islã reconhece o direito ao divórcio, propriedade e herança das mulheres há mais de 1.400 anos, a consciência cristã passou a reconhecer esses direitos somente no século XX e deve-se levar em consideração que a igreja católica, ainda hoje, não reconhece o direito ao divórcio (Grosfoguel, 2008).

Szklarz (2010) analisa que, antes do advento do islã, nas tribos árabes, a honra do homem dependia da fidelidade da mulher. Esse pensamento permitiu a criação dos "crimes de honra", que diminuíram com a chegada do islamismo, uma vez que o Alcorão deu às mulheres direitos anteriormente negados.

São poucas as passagens do livro sagrado que podem ser usadas para justificar práticas culturais patriarcais, e isso fez com que os intérpretes ignorassem os contextos históricos e intertextuais em que os versículos foram revelados e, por isso, pode-se afirmar que a mensagem do Alcorão oferece possibilidades de crítica à dominação patriarcal (Grosfoguel, 2008).

Lima (2014) analisa que autoras feministas islâmicas veem que a divisão das funções na família e na sociedade que buscam justificar a desigualdade não está no Alcorão, e que capítulos deste livro sagrado, que são explicitamente de igualdade, estariam sendo excluídos pela ortodoxia e interpretações tradicionais.

Por exemplo, autoras feministas islâmicas demonstram que o termo qawwamuna'ala, presente nos versículos alcorânicos, "Homens são responsáveis por (qawwamuna'ala) mulheres porque Deus deu a um mais do que o outro (bima faddalan, grifo nosso) e porque eles a apoiam com os seus recursos", transmite a noção de "prover para" o momento do nascimento e da criação, mas ele não significa que a mulher não possa prover sozinha tais recursos. Para elas, o termo qawwamuna'ala não é sobre a autoridade masculina, como supõe a interpretação clássica patriarcal (Lima, 2014:68, apud Badran, 2009: 248).

O Islã mantinha, portanto, em suas raízes, relações de dominação que conectam o homem a mulher nas sociedades muçulmanas, logo, ele seria incapaz de considerar e pôr em prática as mutações sociais e de absorver a modernidade e os direitos humanos. Diferente do que ocorre nas civilizações ocidentais, onde tais direitos foram adquiridos e as mulheres se tornam independentes dos homens, ao se fazer uma breve comparação com a comunidade muçulmana. (Hajjami, 2008: 109)

A reforma promovida pelo Alcorão foi um avanço, mas não tirou a mulher da sua posição inferior e, ao se espalhar pelo norte da África e partes da Ásia e da Europa, o islã foi incorporando costumes locais fazendo com que as interpretações das escrituras sofressem 
influências patriarcais. Já no século XX, a adoção do Wahabismo pela Arábia Saudita em 1920 e a Revolução Iraniana de 1979 complicaram consideravelmente a vida das mulheres islâmicas, adotando medidas que feriam o que era pregado pelo Alcorão. Esses dois acontecimentos foram consequências diretas da derrota do Império Otomano na Primeira Guerra Mundial, uma vez que o califado fora extinto e as terras do islã viraram colônias e, quando conseguiram suas independências, acabaram por estabelecer ditaduras (Szklars, 2010).

Apesar disso, a condição de inferioridade e precariedade a que estão submetidas grande parte das mulheres muçulmanas revela a hegemonia de uma mentalidade e de um sistema patriarcal que instrumentaliza a leitura do Alcorão, utilizando-se assim da religião, para legitimar cenários de dominação, violência e exclusão do protagonismo da mulher na sociedade a qual está inserida (Hajjami, 2008).

Desse modo, existirá dentro do feminismo islâmico um questionamento acerca dos fundamentos da religião de uma perspectiva interna. Os papéis sociais dos homens e mulheres na família e na sociedade islâmica são questionados, ponto esse justificado pelo fato de que a desigualdade não é a proposta do Alcorão, mas sim da dinâmica social aprendida culturalmente (Franco, 2016).

A socióloga e feminista Zahra Ali (2012), autora da obra Féminismes Islamiques, analisou no "painel de discussão de Zahra Ali sobre feminismos islâmicos" ocorrido na França em 2012, que as mulheres que contribuíram para a democratização do conceito de feminismo islâmico são, em sua maioria, mulheres envolvidas em redes intelectuais e militantes que buscam vincular o pensamento sobre questões de gênero no Islã com um compromisso social para melhorar seu status quo e, mais amplamente, contra a discriminação sofrida pelas mulheres muçulmanas.

A autora reforça o ponto principal do feminismo islâmico: a ideia de que o Islã original não promove nenhum tipo de patriarcado, pelo contrário, promove a igualdade de gênero. As feministas islâmicas, então, reivindicam uma leitura e uma releitura das Fontes do Islã usando as ciências sociais para extrair os princípios de igualdade e justiça e distanciar as interpretações patriarcais que foram desenvolvidas através do tempo.

Portanto, pode-se dizer que o feminismo islâmico é um movimento que busca estabelecer a ideia de uma comunidade muçulmana compartilhada entre homens e mulheres, utilizando-se de uma releitura, numa perspectiva feminista, das escrituras sagradas do Islã por meio da livre interpretação das fontes religiosas e da busca pela justiça e pela emancipação das mulheres (Lima, 2014).

Analisando os eventos acima pelo ponto de vista feminista, as fontes de opressão são dinâmicas e complexas, em consonância com o dinamismo das relações sociais no geral em constante estruturação - e, portanto, não podem ser identificadas e fixadas.

No entanto, quando se pensa na diferenciação entre masculino e feminino não como resultado da biologia, mas como um sistema de símbolos sociais definidores do masculino ou feminino, passamos a entender que são estes símbolos - socialmente interpretados 
como decorrentes dos sexos biológicos - que impelem os indivíduos a se comportarem de maneira socialmente entendida como condizente com sua anatomia.

Segundo o Relatório do Fórum Econômico Mundial sobre a Disparidade de Gêneros (2018), até o momento nenhum país alcançou a paridade e que apenas os sete principais países do ranking conseguiram diminuir cerca de $80 \%$ da diferença. Nesse relatório é possível analisar também que o Oriente Médio e o norte da África, juntamente com a África Subsaariana e o sul asiático são regiões que estão abaixo da média ponderada global, estando o Oriente Médio e norte da África em último lugar.

\section{Gráfico 1: Índice global de disparidades de gênero, 2018, por região}

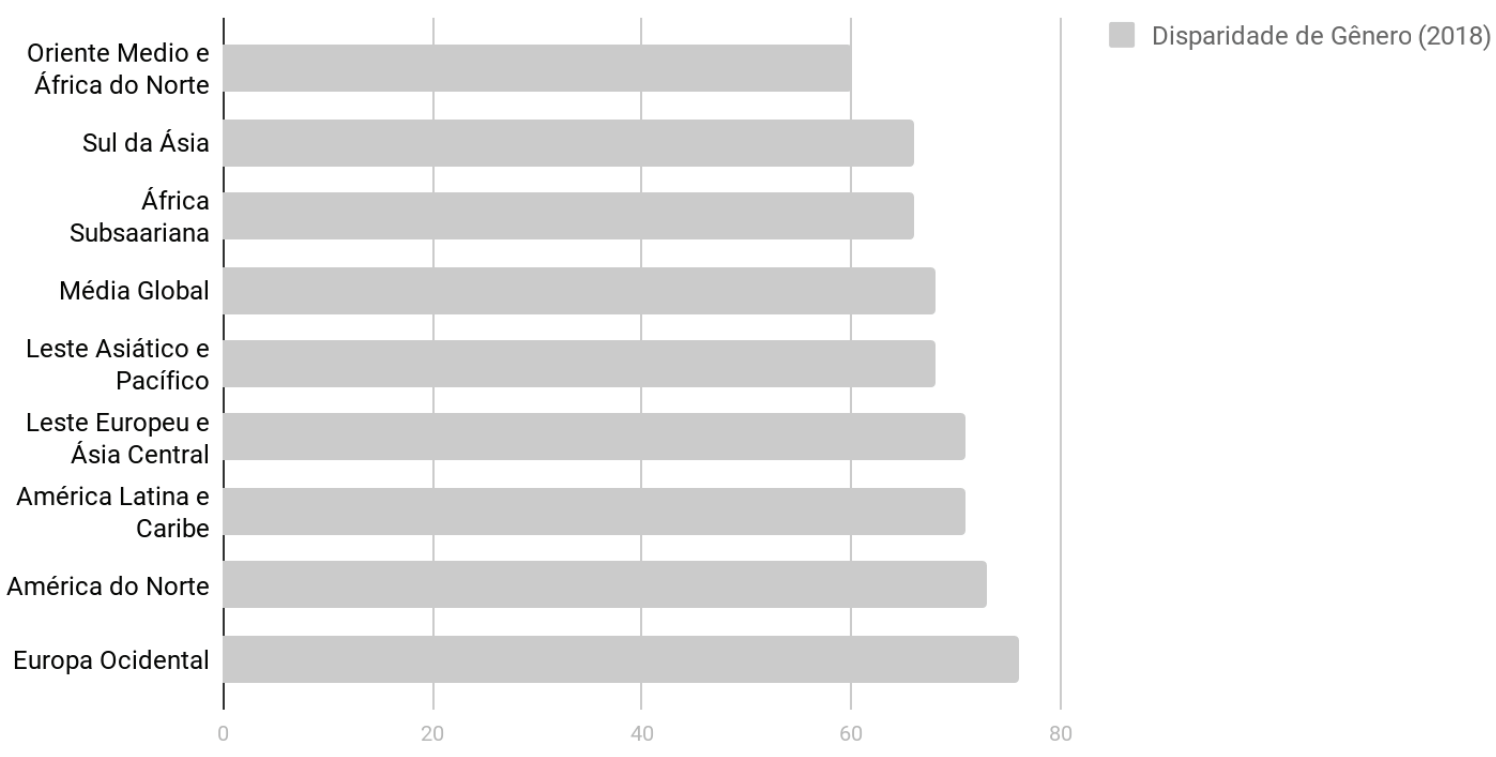

Fonte: Adaptado de WEF, 2018

No entanto, há de se considerar que as mulheres do "Terceiro Mundo" experimentam formas particularmente agudas de opressão por causa das inter-relações. Frente a isso, temos o feminismo pós-colonial, conhecido como anti-imperialista. A sua principal ênfase está na interseção entre imperialismo, colonialismo, capitalismo, racismo e a opressão das mulheres.

As pós-coloniais desafiam a distinção entre o local e o global, afirmando que estruturas de dominação perpassam esses níveis e demonstrando como isso implica formas específicas e múltiplas de opressão para as mulheres do Terceiro Mundo.

0 Ocidente hegemônico sempre buscou maneiras de submeter os discursos dos povos colonizados por meio de um processo histórico de conquistas, imperialismos, cruzadas e de explorações sucessivas. Sendo assim, eram postos como critérios comparativos de processos e experiências, enquanto aqueles que estavam nas margens permaneceram em um referencial de desigualdade, subjugados em uma relação de poder. Os estudos pós-coloniais ressaltam, portanto, essa "diferença colonial" (Mignolo, 2003) e pretendem se desenvolver 
metodológica e teoricamente para que possam oferecer novas formas de pensar sobre técnicas de poder que constrangem a autodeterminação dos povos (Bhabha, 1998).

Edward Said (2007) contribui "para a crítica anticolonial ao denunciar um determinado sistema europeu e eurocêntrico de conhecimentos sobre o 'Oriente' como um corpo criado de teoria e prática com o objetivo de dominar, reestruturar e governar: o Orientalismo". As "relações de poder existentes entre a Europa e um conjunto de países ao leste, maquiadas sob um estilo de pensamento binário Oriente/Ocidente" que esconde "interesses econômicos e políticos bastante específicos" (Chaise, 2016: 10).

Deste modo, a presente teoria visa estudar os confrontos entre culturas, sobretudo as que se encontram ou se encontraram em posição de subordinação, o que caracteriza um cenário de marginalidade colonial nas esferas políticas, culturais, de tempo e de espaço.

Mas, para além do Orientalismo Político, segundo Lila Abu-Lughod, há de se ressaltar o que se convencionou a chamar de "Orientalismo de Gênero", onde a representação estereotipada da "mulher oriental" a partir de lentes ocidentais e - especialmente - a representação desta mulher como oposição à "mulher ocidental" (Abu-Lughod, 2013).

Ainda segundo a autora, ela traz à tona o que denomina de "novo senso comum", onde é acreditado, na percepção ocidental, que as mulheres muçulmanas são oprimidas e isso acontece pela sua própria cultura. Esse tipo de perspectiva desvia o foco das forças sociais e políticas externas que são as reais responsáveis pela maneira como as pessoas vivem a leste da civilização ocidental, incluindo, sobretudo, a extrema pobreza resultante de uma divisão internacional de trabalho injusta e a militarização resultante do combate ao terrorismo. Ademais, mascaram o próprio debate e as lutas por justiça subordinadas a esses países. Ainda, não raro, a questão da mulher é instrumentalizada pela política colonial, a fim de justificar a intervenção política.

Com isso, passa-se a considerar como cultura tudo aquilo que é produzido material ou idealmente pelo ser humano, independentemente de seu grau de complexidade e de desenvolvimento (EAGLETON, 2005). A lógica dessas outras formas de manifestação cultural começou a ser analisada no contexto das estruturas a que a pertenciam. Com fundamento nessa noção de estruturalismo cultural, passou-se à concepção do relativismo cultural.

\section{Relativismo Cultural e os Direitos Humanos}

Hommi Bhabha (1998), então, apresenta a ideia de cultura relacionada à transposição das fronteiras nacionais e culturais. Afirma que, em contraponto às formulações identitárias que procuram aprisionar a cultura, encontra-se a ideia da diferença articulada nas lacunas entre essas fronteiras. Essa diferença não possui o sentido de herança cultural, nem de reprodução da noção de pertencimento conferida pelo local de nascimento, de moradia, ou através da inserção social. Ela é uma expressão de um conjunto de manifestações culturais 
acumuladas, é um fluxo de representações que se encontram nas entrelinhas das identidades externas como a nação.

Aqui, acrescenta-se ainda, o movimento de internacionalização dos direitos humanos, onde dentro das correntes relativistas existem várias perspectivas, que vão desde uma visão mais extremista, denominada de relativismo cultural radical, na qual a cultura é vista como a única fonte de validade de um direito ou regra moral, até uma visão mais amena, denominada de relativismo cultural fraco, onde a cultura pode vir a ser uma importante fonte de validade de um direito ou regra moral.

Segundo Nussbaum (2006), quando se propõe um quadro relativista para avaliar, por exemplo, os direitos das mulheres, enfrentamos três argumentos que merecem atenção: a) o cultural, b) o benefício da diversidade e c) o paternalismo.

Partindo do argumento cultural, muitas pessoas confundem o relativismo cultural com uma certa tolerância à diversidade, com a ideia de que o relativismo apresenta respeito pelas culturas. Mas essa afirmação é refutável, uma vez que a maioria das culturas apresenta considerável intolerância à diversidade. Simplesmente por fazer com que cada cultura detenha a última palavra, nos privamos de uma norma de tolerância geral que poderia ajudar a limitar a intolerância nas culturas. Assim, o argumento cultural é falho.

Deste modo, no debate entre universalismo e relativismo cultural, Abu-Lughod busca negar o universalismo por engendrar as generalizações que nos impedem "de apreciar ou mesmo reconhecer as experiências das pessoas e as contingências com as quais todos vivemos" (Abu-Lugdod, 2013:17). Igualmente, a autora se opõe ao relativismo cultural por perceber que as culturas não são estanques, homogêneas ou isoladas, sendo o produto de uma longa história de interações.

Contudo, o debate sobre os direitos das mulheres muçulmanas deveria ser precedido pelo questionamento sobre a universalidade dos direitos humanos. Nesse sentido, guerras são justificadas através da lógica de identidades opostas e contrastantes. Historicamente, foi assim que o orientalismo, combinado às visões preconceituosas e patriarcais, transformou o feminismo ocidental em uma ferramenta de opressão (Spivak, 2010).

Nussbaum (2006) pondera ainda que o argumento do benefício da diversidade destaca que o nosso mundo é rico em parte porque nem todos concordam com um único conjunto de categorias, mas cada um fala uma linguagem de valor diferente. 0 desafio aqui seria perguntar o quanto a diversidade cultural é parecida com a diversidade linguística ou a diversidade de espécies.

0 problema com essa analogia é que as línguas não prejudicam as pessoas, e as práticas culturais frequentemente o fazem. É interessante acrescentar, como um exemplo, que não é muito claro que realmente haja uma diversidade interessante no tocante às práticas de dominação masculina que as feministas têm tanto contestado. Ser espancada e sofrer de má nutrição possui equivalências semelhantes em todas as culturas, como não ter direitos de possuir terras, não ter voz na política, e desiguais oportunidades de emprego (Nussbaum, 2006). 
Por fim, Nussbaum (2006) apresenta o argumento do paternalismo. Esse argumento diz que ao usarmos um conjunto de normas universais como referência para as sociedades mostramos pouco respeito pela liberdade das pessoas como agentes e cidadãos. Contudo, analisando a relação de um Estado com grupos nacionais que possuem tradições que tratam as mulheres de forma desigual, podemos argumentar que os direitos universais de tolerância religiosa, liberdade de associação e outras liberdades são essenciais para impedir subgrupos de ameaçar formas legítimas de pluralismo. 0 que o sistema internacional de proteção dos direitos humanos deseja são direitos universais que sejam facilitadores da promoção dos direitos humanos e do consenso sobre o mínimo ético irredutível.

\section{FEMINISMO SECULAR E SUA CORRELAÇÃO COM A OCIDENTALIZAÇÃO DO ORIENTE}

As relações entre mulheres fundamentalistas, islamistas e os feminismos seculares muçulmanos se fizeram presentes em muitos países muçulmanos, como na "guerra do véu", que ocorreu na Turquia em 1980, ocasião na qual o governo turco proibiu o uso do véu islâmico em instituições públicas, o feminismo secular turco apoiou o direito de as mulheres islâmicas usarem o hijab; e na elaboração de um primeiro caderno, feito em conjunto por feministas seculares e mulheres islamistas, em um painel de discussão, intitulado "Ao redor do espectro feminista-islamita”, no Cairo em 1995 (Lima, 2014).

Robert Carle (2004) fez um pequeno estudo intitulado "Hijab and the limits of french secular republicanismo". Nesse estudo, o autor aborda que o hijab, mais do que qualquer outro símbolo, força sobre os ocidentais a peculiaridade do Islã, uma vez que mulheres com seus corpos cobertos revelam a importância que as questões de gênero e sexualidade possuem nas críticas que o Islã faz ao Ocidente.

0 autor afirma que o véu islâmico torna o corpo das mulheres muçulmanas uma força política na resistência às forças igualitárias da modernidade ocidental, o símbolo produz mulheres construtoras de modéstia e moralidade e, ao mesmo tempo, faz delas atores poderosos, criando uma identidade pública e coletiva. Como um sinal de islamização, o véu reduz as relações de poder entre Islã e Ocidente; modernidade e tradição; secularismo e religião.

Enquanto as feministas ocidentais veem o corpo velado das mulheres muçulmanas como uma forma de opressão, as mulheres muçulmanas, muitas vezes, veem no véu uma proteção da sexualidade masculina predatória, uma vez que ele preserva os limites entre os sexos, assim como a ordem da comunidade.

Portanto, a questão do hijab está na interseção da miríade de desdobramentos desde 1989, que ressuscitaram e recentralizaram o modelo republicano nacional, entre eles o descrédito das utopias internacionais e da revolução, o aumento da direita neofascista, o aumento do antiamericanismo, a rejeição do multiculturalismo e a fragmentação e recomposição de blocos políticos. As meninas que usam o véu islâmico personificam singularmente esses processos históricos (Ezekiel, 2005). 
No final do seu estudo, Carle (2004) aborda especificamente a crítica feminista ao caso do véu islâmico na França. 0 autor alega que embora os argumentos republicanos dominassem o debate acerca do véu islâmico na França, os sentimentos sobre a questão foram certamente alimentados pela afronta moral que a esquerda sentia a respeito do significado cultural do hijab.

0 direito de estudantes judeus usarem o solidéu e o direito de estudantes cristãos usarem cruzes era protegido nas escolas francesas. Os estudantes têm o direito de tingir seus cabelos de cores diversas, perfurar partes do corpo com piercings e usar roupas rasgadas. Para os secularistas, o hijab é mais ofensivo que qualquer uma dessas práticas. Algumas feministas ocidentais veem o uso do véu islâmico como um símbolo de opressão. Na visão delas, usar cabelos coloridos, roupas rasgadas, calças jeans, entre outros artigos de roupa mais comumente aceitos nas sociedades ocidentais é um gesto de liberdade, enquanto o véu remete à submissão (Carle,2004).

Não é bem assim que as muçulmanas adeptas ao uso do hijab pensam. Galeotti (1993) afirma que o comportamento das meninas muçulmanas possui um significado bem mais amplo do que simplesmente expressar a crença religiosa dessas meninas e mulheres. É uma afirmação pública e até mesmo provocativa da sua participação na comunidade e na cultura islâmica. É um duplo protesto.

O uso do hijab, para além de uma forma de protesto contra a assimilação forçada que o Estado francês exige como condição para a cidadania; contra os preconceitos e estigmas que a comunidade muçulmana sofre por causa de sua cultura, herança étnica e religiosa. É também direito das mulheres não só por sua crença, mas também para defender a sua liberdade de expressão, e principalmente a liberdade de crença. Ao usar o hijab, esses grupos de mulheres se autoafirmam e declaram que são quem querem ser e sentem orgulho disso (Galeotti, 1993).

Portanto, o argumento de emancipação e libertação das mulheres muçulmanas foi central durante a colonização e é justamente a visão colonial do feminismo que serve de base, até os dias atuais, para as reivindicações no "mundo muçulmano" (Ali, 2012). Esse tipo de reivindicação fica conhecida então como sendo a "Batalha do Véu", utilizada por autores como Said (2007).

Carle (2004) afirma também que as culturas minoritárias atualmente estabelecem o princípio da diferença contra o princípio da igualdade, afirmando — criticamente - que o tão aclamado princípio da igualdade reprime as identidades culturais e religiosas. No entanto, é intrínseco que a busca pelo reconhecimento público das identidades e diferenças coletivas é uma exigência fundamental da igualdade infligida através do respeito.

Diferenças sociais que negam visibilidade e legitimidade na esfera pública estigmatizam grupos minoritários ao privar seus membros da liberdade de aparecerem em público sem se envergonhar.

Assim, através desse cruzamento entre o campo feminista secular e o feminismo muçulmano, esse último introduz questionamentos fundamentais nos dois campos: no feminismo 
secular é questionada a dominação do modelo colonial e pós-colonial ocidental que se teria imposto como o único caminho de libertação e emancipação, bem como a ideia de que o feminismo é incompatível aos religiosos e determina uma distância da religião como um todo. No campo muçulmano, ele questiona toda uma série de jurisprudências muçulmanas desenvolvidas através de um ponto de vista patriarcal, denuncia a marginalização do papel e do lugar das mulheres na historiografia muçulmana clássica e a apropriação do conhecimento e da autoridade religiosa dos homens em detrimento das mulheres (Ali, 2012).

\section{UM ORIENTE QUE REJEITA A OCIDENTALIZAÇÃO: COMUNIDADES IMAGINADAS x COMUNIDADES PLURALISTAS}

Conforme Hobsbawm (2003:18-19), "as nações não formam os Estados e os nacionalismos, mas sim o oposto". O sentimento de nação, é, portanto, construído socialmente. E como colocou Sigmund Freud, a convivência intensa em um mesmo território entre cidadãos que gozam de igualdade jurídica geraria um sentimento comunitário baseado em ligações por identificação e sentimentos comuns. Canais de comunicação social são capazes de "fabricar" nacionalidades, já que nacionalidades se transformam em nações quando adquirem poder suficiente para dar suporte às suas aspirações (Einstein, Freud, 1932).

É nesse contexto que a consciência nacional ganha um nome, uma bandeira, uma história seletiva e outros símbolos que distinguem uma nação. A nacionalidade, então, corresponde à pressão do povo para fortalecer-se e, assim, poder controlar seus costumes e impor sua cultura comum. "Nacionalidades tornam-se nações quando adquirem poder para respaldar suas aspirações" (Deutsch, 1969:105)

Em “Comunidades Imaginadas", Benedict Anderson propõe vários nacionalismos, vindos desde a Europa nos séculos XVIII e XIX, sob a predominância popular; ou os ocorridos na América espanhola, com um caráter burguês acentuado pela tensão colônia-metrópole.

Sendo assim, Lilia Schwarcz (apud Anderson, 2008:10) coloca que "nações são 'imaginadas', no sentido de que fazem sentido para a 'alma' e constituem objetos de desejos e projeções". Remetendo assim para a análise construtivista das Relações Internacionais, que parte do princípio de que as nossas relações e realidades são socialmente construídas através de uma troca mútua e constante entre os agentes (nós) e a estrutura (o Estado).

B. Anderson (2008:32-35), vem, portanto, definir:

Uma comunidade política imaginada (...) como sendo intrinsecamente limitada e, ao mesmo tempo, soberana. (...) imaginada pois seus membros jamais se conhecerão ou se encontrarão, embora todos tenham em mente a imagem viva da comunhão entre eles. A única coisa que pode dizer que uma nação existe é quando muitas pessoas se consideram uma nação; limitada porque possui fronteiras finitas e nenhuma delas imagina ter a mesma extensão da humanidade. Nem os nacionalistas mais messiânicos sonham com o dia em que todos os membros da espécie humana se unirão à sua nação; soberana por ser laica e independente de uma dinastia ou de uma ordem divina; [por fim] é imaginada como uma comunidade porque, independente da desigualdade e da exploração 
que possam existir dentro dela, a nação sempre é concebida como uma profunda camaradagem horizontal.

Em 2011, durante o governo Obama, os Estados Unidos da América utilizaram a imagem de mulheres impossibilitadas de frequentar escolas para suscitar apoio nacional e internacional para intervir no Oriente Médio e promover a guerra contra o terrorismo. Nesse momento, foi evidenciada a ligação direta entre a promoção dos direitos das mulheres árabes e a luta contra o terrorismo, com o objetivo de justificar os bombardeios americanos no Iraque e no Afeganistão.

O Ocidente hegemônico sempre buscou maneiras de submeter os discursos dos povos colonizados por meio de um processo histórico de conquistas, imperialismos, cruzadas e de explorações sucessivas. Sendo assim, eram postos como critérios comparativos de processos e experiências, enquanto aqueles que estavam nas margens permaneceram em um referencial de desigualdade, subjugados em uma relação de poder. Os estudos pós-coloniais ressaltam, portanto, essa "diferença colonial" (W. D. Mignolo, 2003), e pretendem se desenvolver metodológica e teoricamente para que possam oferecer novas formas de pensar sobre técnicas de poder que constrangem a autodeterminação dos povos (Homi Bhabha, 1998).

Rita Abrahamsen (2007) analisa que as Relações Internacionais são reconhecidas como sendo a disciplina do Ocidente rico e o pós-colonialismo um estudo "marginal", apresentando o mundo através da perspectiva do subalterno e como ele percebe a realidade ao seu redor. Se configurando, também, como um estudo de fronteira, quer seja entre as disciplinas, quer seja entre os grupos nacionais e étnicos, entre excluídos e incluídos, haja vista que procuram questionar tais barreiras para que se firme novos espaços e relações (Nogueira; Messari, 2005).

A igualdade de gênero é um tema central no debate mais amplo que questiona se o Islã se encaixaria ou não nas regras seculares europeias, nos parâmetros de democracia e direitos humanos. Gayatri Spivak (2010) denunciou que algumas das críticas mais radicais produzidas pelo Ocidente hoje são o resultado de um desejo interessado em manter o Ocidente como sujeito principal.

A mulher muçulmana é quase sempre representada como vítima de um véu que apaga todos os traços de identidade, mulheres transformadas em uma massa uniforme, tristes e submissas, vestidas de preto da cabeça aos pés e submissas aos homens da sua sociedade.

Estes homens muçulmanos, inseridos na mesma lógica, são facilmente classificados como um inimigo desconhecido, principalmente em épocas de crise e insegurança. Segundo Renata Pepicelli (2008:92), "planos de cooperação internacional, da mesma forma que intervenções armadas, se justificam como atos de defesa dos Direitos Humanos, e dos direitos das mulheres, particularmente".

Esse "inimigo desconhecido" acaba gerando nas pessoas uma generalização cultural, colocando, novamente, árabes e muçulmanos como sinônimos. Mas essa generalização não é inédita, ela já aparece nos primórdios do Orientalismo, Said (2007:51) analisa que "a força cultural não é uma coisa que podemos discutir facilmente". 
Indo contra esse viés, o Orientalismo se tornou abrangente justamente porque, para essa corrente, a denominação "oriental" resulta numa exultação, ora amadora, ora profissional por tudo o que seja asiático, sinônimo de exótico, misterioso e profundo (Said, 2007:61). "[...] o Oriente e o oriental, fosse este árabe, islâmico, indiano, chinês ou qualquer outra coisa, tornaram-se encarnações repetitivas de algum original grandioso" (Said, 2007:72).

Desse modo, fica evidente que no mundo Ocidental é comum pensar nas mulheres muçulmanas e árabes como um grupo monolítico, visto que com frequência o termo que se refere a etnia (árabe) é confundido com o que identifica a religião (muçulmano). Assim, faz-se necessário uma análise menos superficial sobre a religião islâmica e seus significados para que possamos entender as lógicas locais desse "oriente islâmico".

0 feminismo islâmico possui muitas ativistas que cresceram e estudaram fora das esferas de influência do Islã, em sociedades "mais ocidentalizadas". Isso faz com que o movimento tenha força em países como Turquia e Egito, que possuem um histórico de intercâmbios de pensadores com o ocidente e se relaciona com a secularização e com outros elementos típicos da pós-modernidade, como a racionalização, a globalização, o multiculturalismo, a democratização, o individualismo e a fragmentação dos discursos.

Nessa esfera, a socióloga marroquina Fatima Mernissi é reconhecida como pioneira nos estudos feministas islâmicos, a partir de sua obra Women and Islam: an historical and theological inquiry (1991), apesar da mesma declarar-se feminista secular (Lima, 2014).

Assim, Talal Asad $(1986 ; 1996)$ trata, entre outros elementos, do pluralismo cultural no Islã e de como há um equívoco na visão de estudiosos ocidentais que acabam tendo o referencial ocidental para o julgamento de um universo que possui outros significados simbólicos.

De um modo geral, para os ocidentais seculares o islamismo e seu código de valores desrespeitam lutas históricas ligadas à emancipação das mulheres e outras pautas dos direitos humanos dura e - ainda - parcialmente conquistadas.

Nesse sentido, o feminismo islâmico acaba por se encontrar em uma fronteira de difícil negociação em relação a outros grupos feministas e a outros movimentos sociais.

Considerando que uma característica dos movimentos sociais é o self help (Tickner, 1992), uma articulação das minorias sociais, em nome de um fortalecimento identitário de combate a opressões e reafirmação da essência do Islã, pressupõe-se que o feminismo islâmico, por conta das características apontadas acima, enfrenta um isolamento político, ou ao menos uma desconfiança de seus pares.

A nova consciência de gênero emergente no feminismo islâmico situa-se nas fronteiras entre as perspectivas seculares e as perspectivas religiosas islâmicas, e tem-se o entendimento de que tais fronteiras - porosas, ambíguas e conflituosas - podem trazer um isolamento político ao movimento do feminismo islâmico por este guardar em suas raízes e propostas o vínculo com uma religião identificada, no genérico mundo ocidental, como fundamentalista e mantenedora de práticas misóginas, patriarcais e que reforçam as desigualdades de condição. 


\section{CONSIDERAÇõES FINAIS}

Ao pensar-se em feminismo, seria necessário iniciar qualquer assunto associando os termos "mulher" e "islã" para a tentativa de desconstruir o sujeito e ainda lidar com a questão das "mulheres no Islã", seu status quo e, mais ainda, a compreensão de que a "mulher islâmica" é fruto de uma construção social e histórica, que faz com que essas mulheres se encontrem às margens do contexto global, como se ser mulher dentro do Islã fosse diferente em ser mulher dentro de qualquer outra sociedade ou civilização.

A trajetória de luta do feminismo islâmico constitui a história recente e, desde que a sua discussão foi trazida à tona, essa vertente teórica enfrenta diversos desafios. De um lado, existe seu isolamento em relação a outros grupos feministas seculares em função do tipo de discussão desenvolvida internamente e, principalmente, por apoiar-se em modelos teóricos que veem as religiões como fonte de muitos dos males a serem superados.

Por outro lado, o feminismo islâmico enfrenta, no seio da própria cultura muçulmana, riscos inerentes aos enfrentamentos severos aos quais se propõe. Às interseccionalidades de sexo, raça e classe deve ser adicionado o reconhecimento das assimetrias globais e das hierarquias de poder entre países. Ainda, busca-se realizar a análise das causas de subordinação de gênero dentro de contexto cultural específico, ressaltando-se história, memória e ética e recusando-se uma compreensão universalista das pretensas necessidades " $d a$ mulher" - que leva a uma visão das mulheres do Terceiro Mundo como "vítimas a serem salvas" - e também o artifício do relativismo cultural, que engessa as possibilidades de crítica à realidade de opressão de gênero (L. Abu-Lughod, 2013).

No decorrer do presente trabalho, buscou-se desconstruir a imagem do Oriente pelas lentes ocidentais caracterizada como uma sociedade arcaica, obscura e perigosa se comparada com os ideais progressistas, modernos e igualitários do outro lado. Com isso, justifica-se a dominação cultural trazida pela vertente pós-colonial, mas traz sobretudo o tema da opressão das mulheres muçulmanas e seu hijab frente a missão "civilizadora" do ocidente.

Há ainda um imenso caminho a ser trilhado no sentido de emancipação do lugar de sujeito histórico das mulheres islâmicas, mas principalmente segue-se a mensagem de que existe entre as mulheres de véu uma consciência emergente de gênero que resiste às opressões de elementos culturais associados à interpretação dos princípios religiosos do Islã, assim como resiste às pressões de "ocidentalizar-se".

É interessante perceber que o próprio termo "feminista" é cada vez menos rejeitado nas esferas muçulmanas e é cada vez mais redefinido e renunciado (Ali, 2012). Há que se construir um novo modelo de sociedade nestas fronteiras, e um grupo de mulheres parece estar genuinamente disposto a este desafio. Essa "reinvenção" do feminismo como um projeto de política transnacional, já apontado por Nancy Fraser (2007), adiciona criticidade também à disciplina Relações Internacionais, na qual é visível no seu mainstream teórico o ocultamento da questão de gênero. 


\section{REFERÊNCIAS}

ABRAHAMSEN, Rita. Postcolonialism. In: GRIFFITHS, Martin. International Relations Theory for the Twenty-First Century: An Introduction. New York: Routledge, 2007.

ABU-LUGHOD, Lila. "Orientalism and Middle East Feminist Studies". Feminist Studies, v. 27, n. l, p. 101-113, 2013.

ALI, Zahra. "Femmes, féminisme et islam: décoloniser, décloisonner et renouveler le féminisme". 2012. Disponível em: <http://frontdu20mars.github.io/Textes/2012/07/06/ femmes-feminisme-et-islam-decoloniser-decloisonner-et-renouveler-le-feminisme.html $>$. Acesso em: 29 ago. 2019.

ANDERSON, Benedict. Comunidades Imaginadas. São Paulo. Cia das Letras, 2008.

ASAD, Talal. "The Idea of an Anthropology of Islam". Center for Contemporary Arab Studies, Georgetown University, 1986.

BHABHA, Homi. K. O local da cultura. Tradução: Myriam Ávila, Eliana Lourenço de Lima Reis e Gláucia Renate Gonçalves. Belo Horizonte: Editora UFMG, 1998.

CARLE, Robert. "Hijab and the limits of French secular republicanism". Society. v. 41, n. 6, pp. 63-68, set, 2004.

CHAISE, Mariana Falcão. “Feminismo Transnacional: uma lente para o Anti-Orientalismo". Revista Estudos Feministas, v. 24, n. 3, p. 1027-1030, 2016.

DEUTSCH, K. W. Análise das Relações Internacionais, Brasília: Editora Universidade de Brasília, 1969.

EAGLETON, Terry. A idéia de cultura. São Paulo: Ed. Unesp, 2005.

EINSTEIN, Albert; FREUD, Sigmund. Why War? Instituto Internacional para Cooperação, 1932.

EL HAJJAMI, Aïcha. "A condição das mulheres no Islã: a questão da igualdade”. Campinas: jun., n. 30, p. 107-120. 2008. Disponível em: <http://www.scielo.br/scielo.php?script=sci_arttext\&pid=S0104-83332008000100009\&lng=en\&nrm=iso>. Acesso: 23 maio 2019.

ENLOE, Cynthia. Maneuvers - The Politics of Militarizing Women's Lives. Berkley and Los Angeles: California University Press, 2000.

EZEKIEL, Judith. "Magritte Meets Maghreb: This Is Not a Veil”. Australian Feminist Studies. v. 20, n. 47, pp. 231-243. jul. 2005.

FRANCO, Clarissa de. "Feminismo islâmico face ao feminismo secular: uma nova consciência de gênero de um oriente que rejeita a ocidentalização". São Paulo: Último Andar, n. 27, p.84-92, 2016. Disponível em: <https://revistas.pucsp.br/ultimoandar/article/view/27095>. Acesso em: 29 ago. 2019. 
FRASER, Nancy. "Mapeando a imaginação feminista: da redistribuição ao reconhecimento e à representação: da redistribuição ao reconhecimento e à representação". Revista Estudos Feministas, [s.l.], v. 15, n. 2, p. 291-308, ago. 2007. Disponível em: <http://dx.doi.org/10.1590/ s0104-026x2007000200002>.

GALEOTTI, Anna Elisabetta. “Citizenship and Equality: The Place for Toleration”. Political Theory: 1 nov. 1993, v. 21, n. 4, pp. 585 - 605.

GROSFOGUEL, Ramón. "Para descolonizar os estudos de economia política e os estudos pós-coloniais: transmodernidade, pensamento de fronteira e colonialidade global". Revista Crítica de Ciências Sociais, n. 80, p. 115-147, mar. 2008.

HARDING, Sandra. The Science Question in Feminism. Ithaca, NYC: Cornell University Press, 1986.

HOBSBAWM, E. J. Da revolução industrial inglesa ao imperialismo. 5. ed. Rio de Janeiro: Forense Universitária, 2003.

LIMA, Cila. "Um recente movimento político-religioso: feminismo islâmico". Estudos Feministas, v. 22, n. 2, p.675-686, ago. 2014.

MESSARI, Nizar; NOGUEIRA, João Pontes. Teoria das Relações Internacionais: correntes e debates. Rio de Janeiro: Elsevier, 2005.

MIGNOLO, Walter D. “Novas reflexões sobre 'Ideia da América Latina': a direita, a esquerda e a opção descolonial". Caderno CRH, v. 21, n. 53, p. 239-252. 2003

NÓRA, Laura Rodrigues. “O Complexo de Salvador Ocidental: Pós-colonialismo e Feminismo no Oriente Médio”. Cadernos de Relações Internacionais/PUC - Rio, v. 1. abr. 2018.

NUSSBAUM, Martha. In Defence of Universal Values. In: MULLER, Adam (Org.). Concepts of Culture: art, politics \& society. Alberta: University of Calgary Press, 2006.

PEPICELLI, Renata. "Islamic feminism: identities and positionalities. Why keep asking me about my identity? Thoughts of a non-Muslim, in Islamic Feminism: Current Perspectives, Tapri Occasional Papers, Tampere, Tampere Peace Research Institute”, 2008, pp. 91-102.

SAID, Edward W. Orientalismo: o Oriente como invenção do Ocidente. São Paulo: Companhia das Letras, 2007.

SPIVAK, Gayatri. Pode o subalterno falar?. Belo Horizonte: EDUFMG, 2010.

SZKLARZ, Eduardo. "Sob o véu: o Alcorão é muito mais tolerante com as muçulmanas do que as culturas e os governos de onde vivem. Saiba como mudou, ao longo da História, a condição da mulher no Islã." Aventuras na História, pp. 28-33, jul. 2010.

TICKNER, J. Ann. Gender in International Relations: Feminist Perspectives on Achieving Global Security. New York: Columbia University Press, 1992.

WORLD ECONOMIC FORUM. The Global Gender Gap Report 2018. 2018. Disponível em: <http://reports.weforum.org/global-gender-gap-report-2018/> Acesso em 25 maio 2019. 